\title{
ADAPTATION OF A MID-NINETEETH CENTURY REPRESENTATIVE UNIVERSITY BUILDING TO OFFICE FUNCTIONS
}

\author{
J. SZOLOMICKI ${ }^{1}$, M. MINCH ${ }^{2}$, G. DMOCHOWSKI ${ }^{1}$ AND P. BERKOWSKI ${ }^{1 *}$ \\ ${ }^{1}$ Faculty of Civil Engineering \\ Wroclaw University of Science and Technology \\ Wyspianskiego Blvd. 27, PL50-370 Wroclaw, Poland \\ grzegorz.dmochowski@pwr.edu.pl, \\ piotr.berkowski@pwr.edu.pl (*corresponding author), \\ jerzy.szolomicki@pwr.edu.pl \\ ${ }^{2}$ VEGACAD Design and Implementation Office \\ 89, Agrestowa Str., PL53-006 Wroclaw, Poland \\ minch@vegacad.com.pl
}

Keywords: Historical Building, Masonry, Revitalization, Structural Solutions, Construction

\begin{abstract}
The rehabilitation of historical buildings plays an important role in enhancing the sustainable built environment of a city. Re-use of old buildings when adapting them to new functions has become a common way to protect the significance of historical buildings and keep them for future generations as examples of the achievements of former architects and construction masters. Issues connected with the adaptation of an old university three-story building from 1866 that has exceptional artistic qualities is the subject of the analysis presented in this paper. Originally, the building was multifunctional, and intended for the activities of various university units. During the II World War, the main body of the building was seriously damaged. After the war, the building was reconstructed using the current building materials and construction solutions, and was handed over to the Medical Department of Wroclaw University. The building is now undergoing renovation, the purpose of which is to change its function into an office building. The greatest value of the building is its façade - with excellent proportions - which perfectly fits into the spatial context and the development of this part of the city. For this reason, the preservation of the building's main structure was the most important aspect of the renovation design process. The paper presents the results of the assessment of the building's technical state, analysis of the planned functional changes and renovation ideas, and finally, a description of the structural and constructional solutions adopted to solve the problems occurring during the renovation works.
\end{abstract}

\section{HISTORICAL OUTLINE OF THE FORMER UNIVERSITY BUILDING}

The building, with its exceptional artistic value (Fig. 1), was designed by the outstanding Wroclaw architect Theodor Milczewski and put into use in 1866 [1]. 


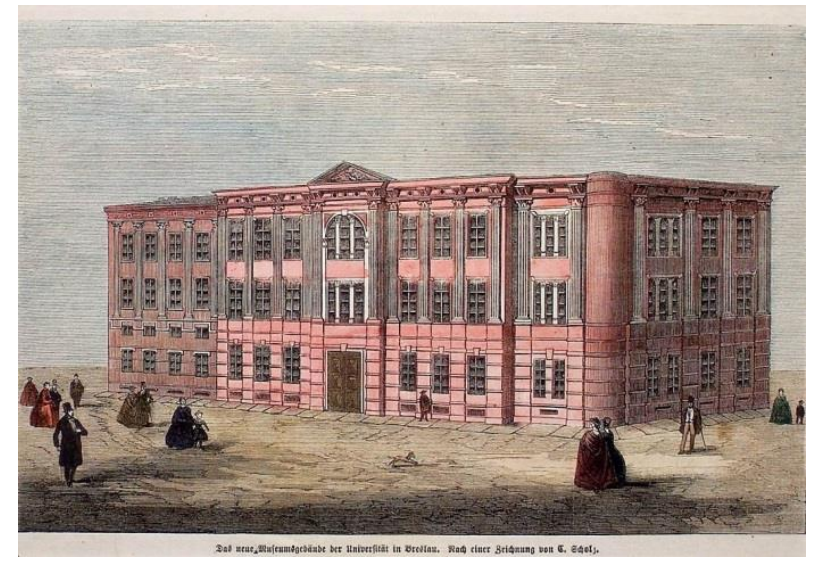

Figure 1: General design view (from north) of the building presented in a newspaper from 1866 [2]

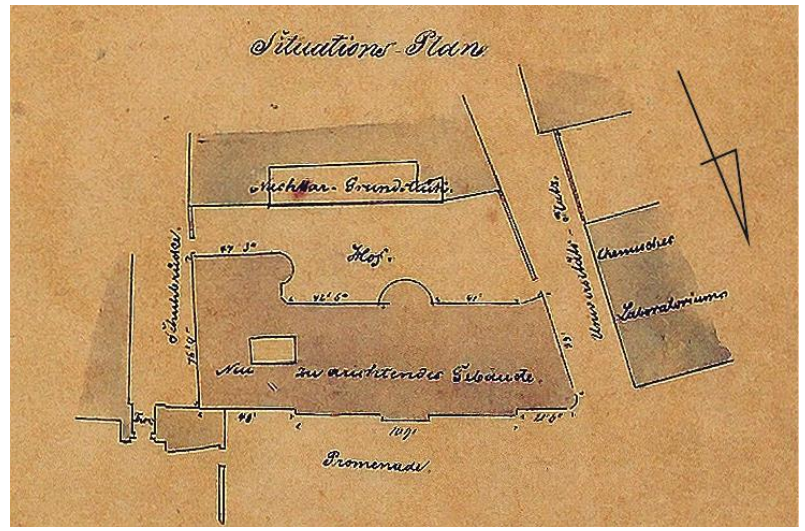

Figure 2: Location of the considered building within the city environment (1864) [3]

The three-story building was located on Grodzka Street (Burg Str.), which ran along the promenade by the Odra river (Fig. 2). The building filled the entire northern part of the area between Szewska Street (Schuchbrücke Str.) and Uniwersytecki Square (Universität Platz). From the east it was adjacent to the middle school of St. Maciej that was located in the baroque Monastery of Crusaders of the Red Star, and from the west it was adjacent to the

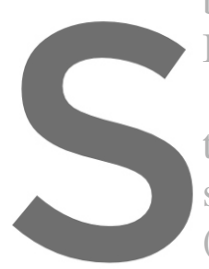
Institute of Chemistry that was erected 10 years earlier.

The main entrance to the building (Fig. through a representative vestibule and syi short side wing was erected on Szewska Stree (Fig. 4). The Pharmac Institute was located

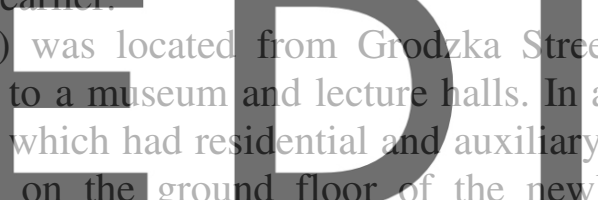

building. It continued the traditions of the university pharmacy, which was founded by the

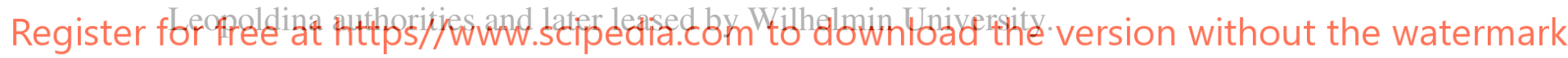

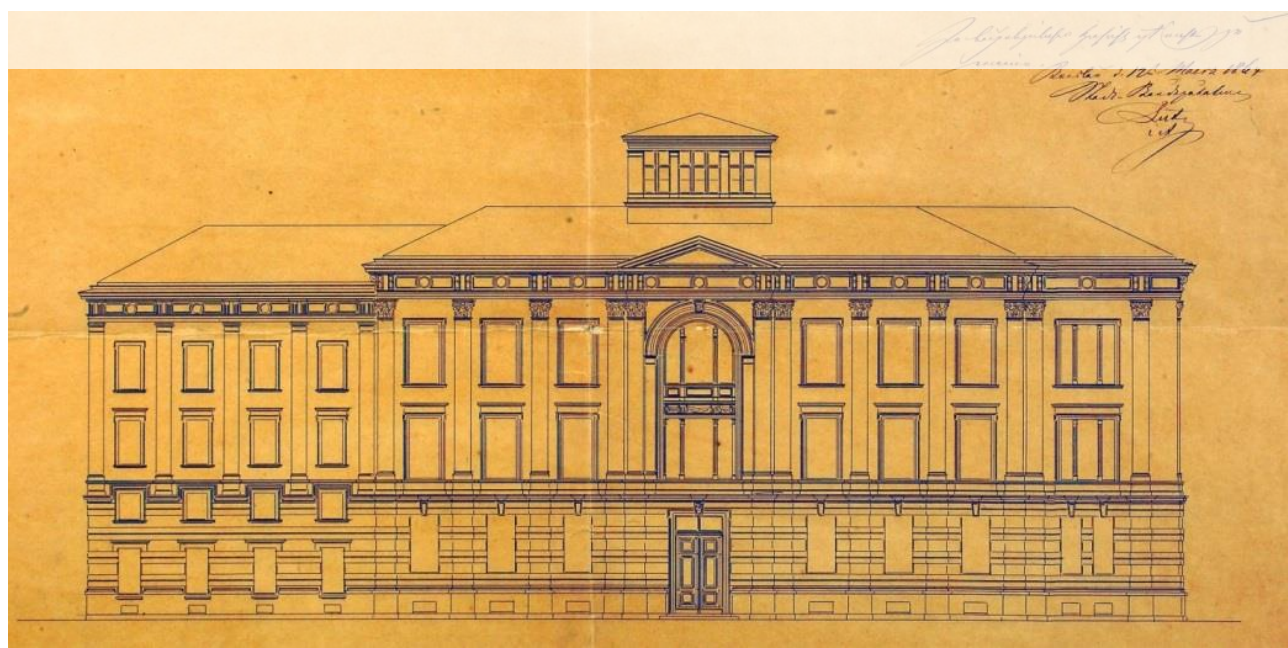

Figure 3: Archival view of the front (northern) building elevation (1864) [3] 
The museum that was located on the upper floors of the building collected and presented mineralogical, petrographic and paleontological collections. The lower wing along Szewska Street initially had mainly residential functions: on the full floors there were flats with several rooms for researchers, while in the mezzanine above the ground floor there were three smaller flats for servants and watchmen. Over time, the residential function gradually gave way to the need to arrange an increasing number of offices for researchers.
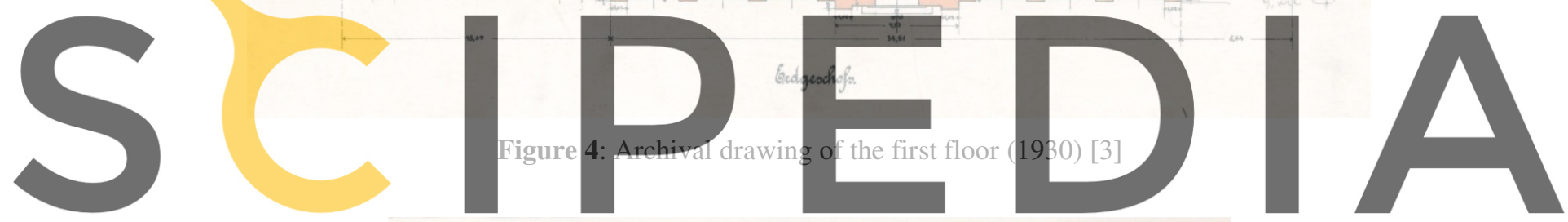

Register for free at https//www.scipedia.com to download the version without the watermark

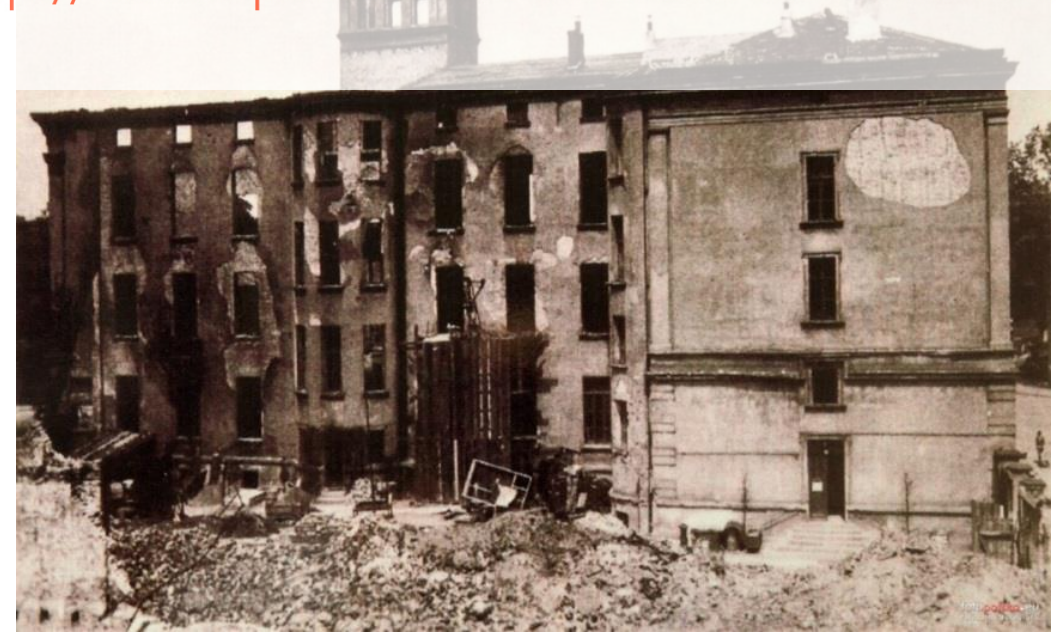

Figure 5: View of the destroyed building in 1945 (southern side) [4] 
During the war in 1945, the main body of the building was seriously damaged (Fig. 5). The eastern part of the building, which included the entire lower wing along Szewska Street that was originally residential, survived without any major damage to its body and slate roof. In turn, the main body of the building was completely burned out, and the part located on the west of the vestibule and the main staircase was demolished to ground level. The ruined building was handed over to the Faculty of Medicine of Wroclaw University and to Wroclaw University of Science and Technology. It was meant to be the location for the Pharmaceutical Department.

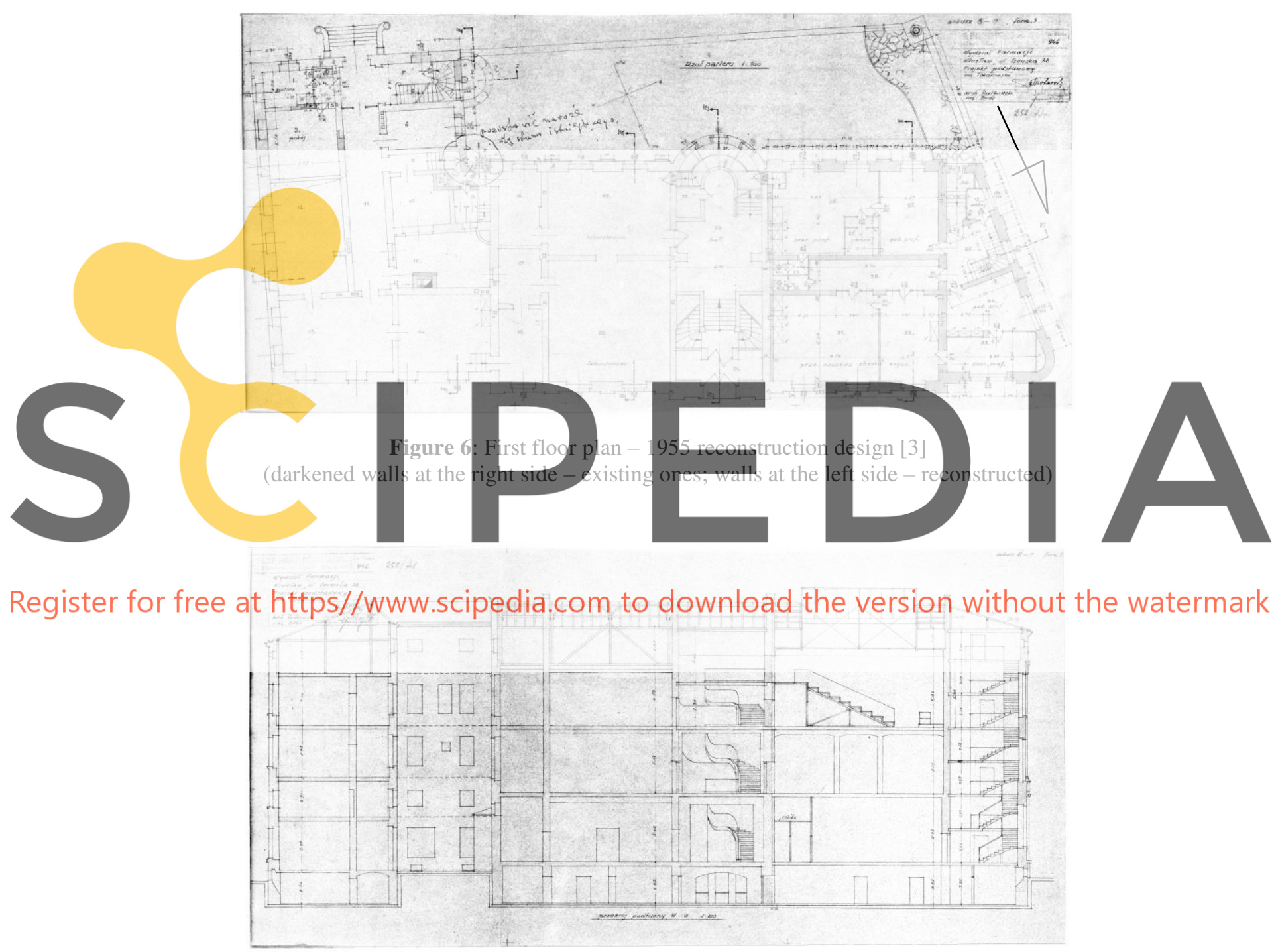

Figure 7: Cross-section VI-VI (east-west direction) of the building - 1955 reconstruction design [3]

The renovation of the eastern part of the building, with the main staircase and vestibule, was completed in 1948. A provisory lecture room on the first floor, and a workshop for inorganic and analytical chemistry on the second floor, were opened at that time. The 
reconstruction of the west wing began in 1955 (Figs. 6, 7). Renovation work included the construction of new floors. A reinforced concrete slab was made above the basement where the bunker was planned, while in the rest of the basements and on the upper floors there were massive dense ribbed floors. In addition, steel roof trusses with a skylight were made above the auditorium room.

\section{THE STRUCTURAL LAYOUT AND DIAGNOSIS OF THE TECHNICAL STATE OF THE BUILDING}

\subsection{The building's current architectural and structural elements}

The analyzed building is a freestanding object, situated on a plan that is similar to the letter L, and consisted of two parts: the west and east wings (Fig. 4). The building has three floors above ground (a ground floor and two upper floors), an unused attic, and a basement. In the east wing there is an additional floor between the ground floor and the first floor - the mezzanine (Fig. 8).
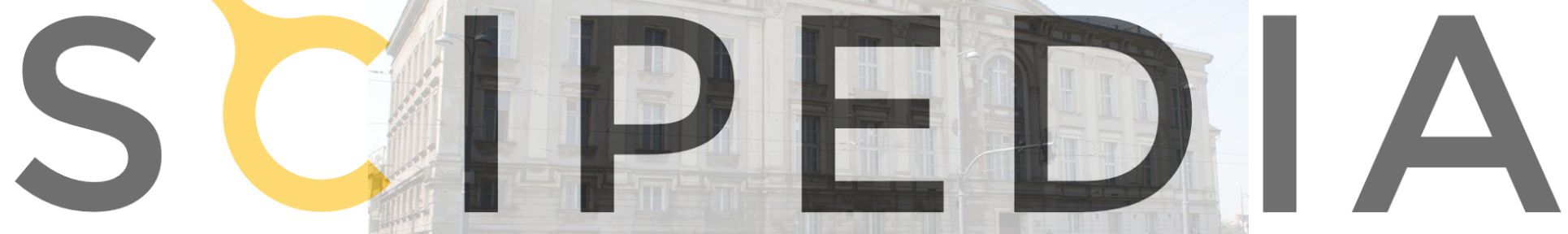

Register for free at https//www.scipedia.com to download the version without the watermark

Figure 8: Current view (from north) of the front façade of the building

The greatest value of the building can be seen to be its historic front (northern) façade, and its body with excellent proportions, which perfectly fits into the spatial context of the estate. The façade from the Grodzka Street side is distinguished by a seven-axis avant-corps. The entrance portal is located on the axis of the apparent avant-corps. Above the portal, there is a two-storey triple window, which is finished with a full arch, enclosed by an arcade that is supported on Tuscan pillars, and topped with a keystone with a carved head.

The in between window pillars and small pilasters that support the cordon cornice, which are placed on the line of pediments of the other windows of the first floor, have decorative details in the form of the Doric order. Above the façade axis there is a tall, three-axle belvedere. The four-axis façade of the lower side wing is expressed similarly to the facade of the body. The eight-axis eastern (side) façade is also preserved in a similar style, however, the Tuscan pilasters only decorate the corners of the building. 
The foundation of the building is in the form of brick continuous footings, with or without offsets. Under part of the continuous footings there is a foundation made of stone boulders, which may indicate that the previously existing foundations were locally used as a foundation of this building. The width of the continuous footings is from 0.75 to $1.00 \mathrm{~m}$, and the height is about $1.90 \mathrm{~m}$. The depth of the foundation of the continuous footings is $3.35 \mathrm{~m}$ below the existing terrain, and $1.85 \mathrm{~m}$ below the existing floors in the basement. The main structural system of the building consists of walls made of solid brick with varying thicknesses (Figs 4, 6 \& 7). The basement walls are made of solid brick, and have the following thicknesses: external walls from 0.38 to $1.00 \mathrm{~m}$, and internal structural walls from 0.38 to $0.80 \mathrm{~m}$. Horizontal wall insulation was found, but there is no vertical insulation. The upper wall thicknesses amount to approx. 1.02 to $0.64 \mathrm{~m}$ for the external walls, and from 1.02 to $0.38 \mathrm{~m}$ for the internal structural walls.

The completed structural inventory showed a very large variety of types and systems of floors. In the eastern wing, segmental vaults and the Klein floor on steel beams were found above the basement. The upper storeys have wooden floors and locally Klein slabs. The west wing is even more diverse in terms of its floor structures. Above the basement there are segmental vaults, prefabricated ribbed floors, and also reinforced concrete slabs. On the upper floors there are prefabricated floors, Ackermann slabs, and reinforced concrete slab floors. The roof structure is also not a homogeneous solution for the entire building. There are classic wooden purlin-rafter and suspension systems in the east and west wings, and a completely different arrangement of steel trusses above the auditorium in the west wing (Fig.7)

\subsection{The diagnosis of the technical state of the building

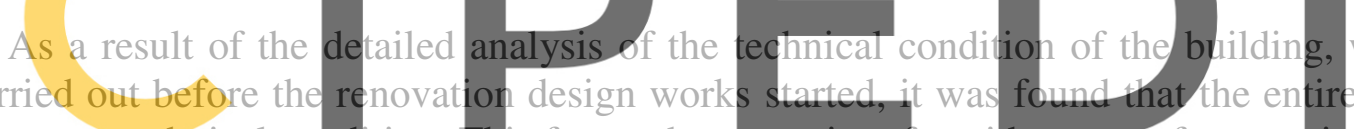 in a poor technical condition. This forces the nect}

be carried out. The reason for the building's condition was primarily due to its long-term

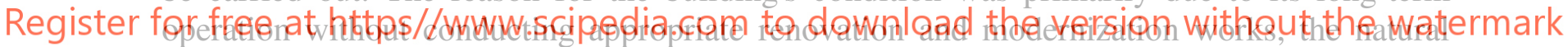
wear of the used materials, and also environmental impacts.

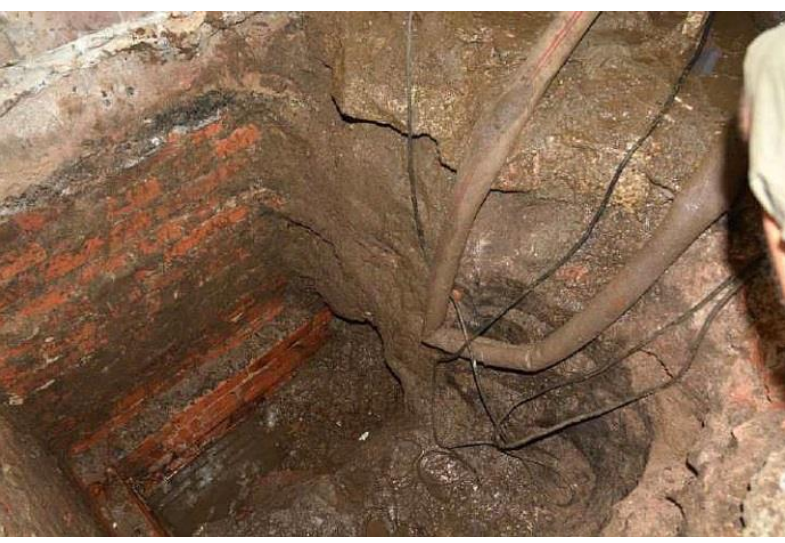

Figure 9: Exposure of the foundation walls

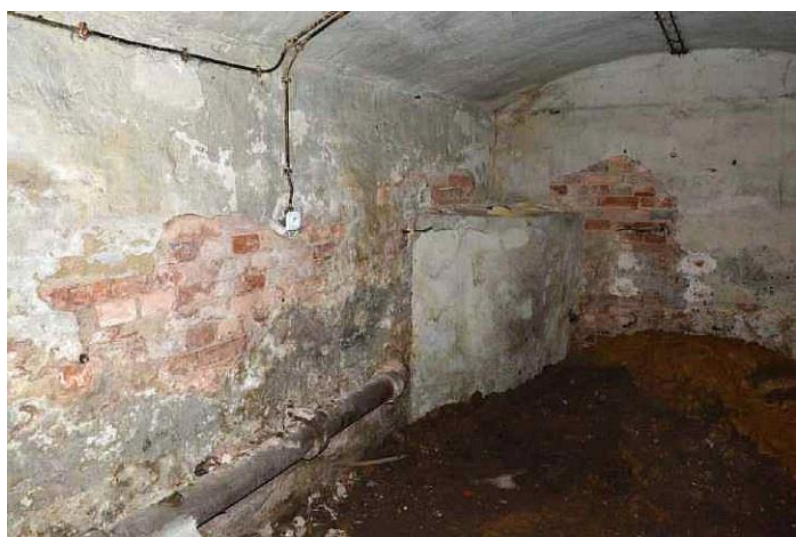

Figure 10: High dampness of the basement walls 
With regards to the condition of the foundations, and based on the conducted exposure works (Fig. 9), it was found that they were probably made at a variable level of the loadbearing soil layers. In addition, the level of groundwater in the vicinity of the building is above the level of the native load-bearing soils, and a quick water flow into the executed excavations was observed. It was also found that all the basement walls have a very strong moisture content - the existing horizontal insulation no longer fulfills its function (Fig. 10). It was necessary to dry the walls and to at least make horizontal insulation using the injection technique.

Static calculations showed that the foundations of the left internal walls do not have a sufficient load-bearing capacity to transfer the designed loads. These foundations must be reinforced by e.g. jet-grouting. In addition, due to increased vibrations that are generated by trams passing on the neighboring Szewska Street, it was also recommended to jet-grout the wall of the building along this street. However, the analysis of the working conditions of the entire facility after strengthening the foundations showed that jet-grouting of only part of the walls will change the rigidity of the entire building and may contribute to the cracking of walls in different places. Therefore, for the implementation of the modernization project, it was recommended to strengthen the foundations of all the load-bearing walls of the building.

In the external walls, nearly all the brick window lintels and the under-sill walls located underneath them have been scratched or cracked. However, the largest extent of damage occurs in the wall that is located by the street that is loaded with tram traffic (Figures 11, 12,

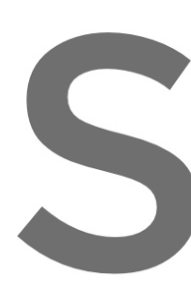
13). Consequently,

windowsill walls shou
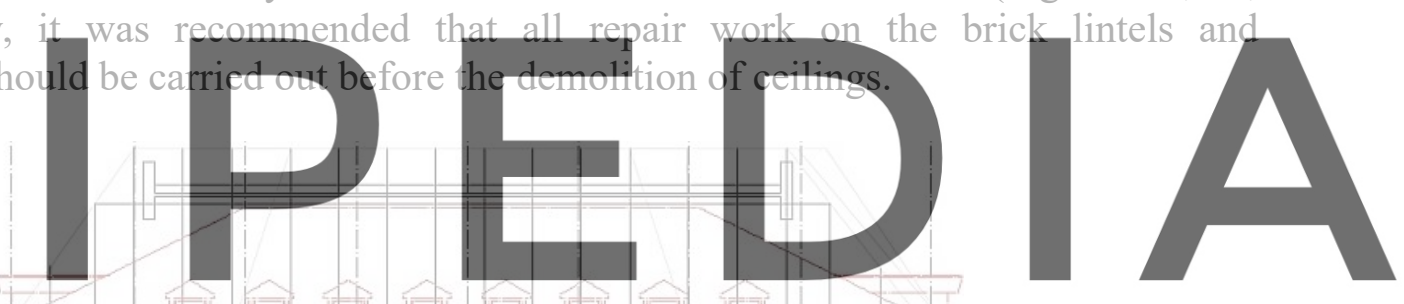

Register for free at https//WwW.scipedia.com to download the version without the watermark

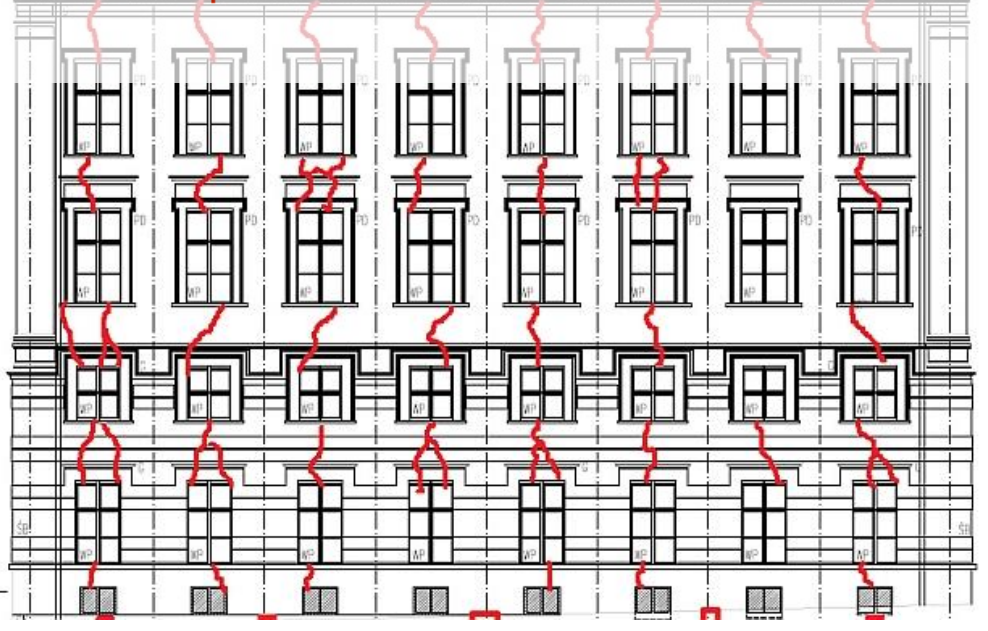

Figure 11: The location of cracks in the side (eastern) façade lintels and wall 


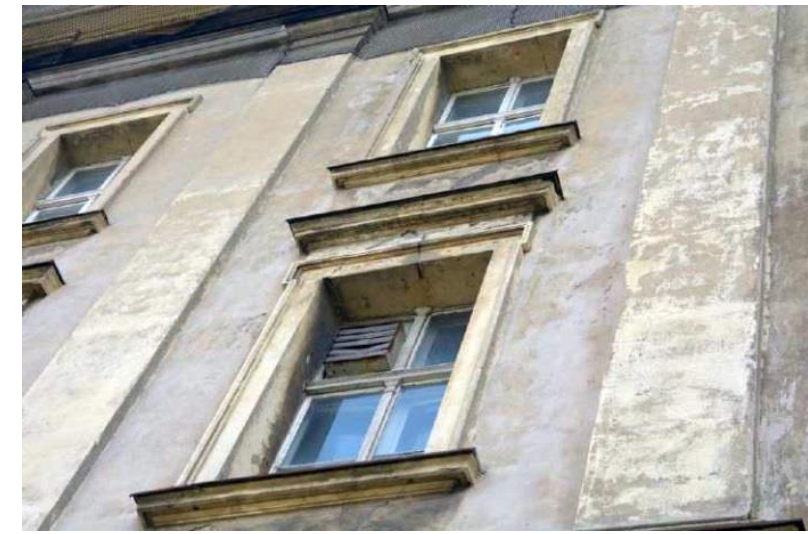

Figure 12: Example of cracks in lintels and walls

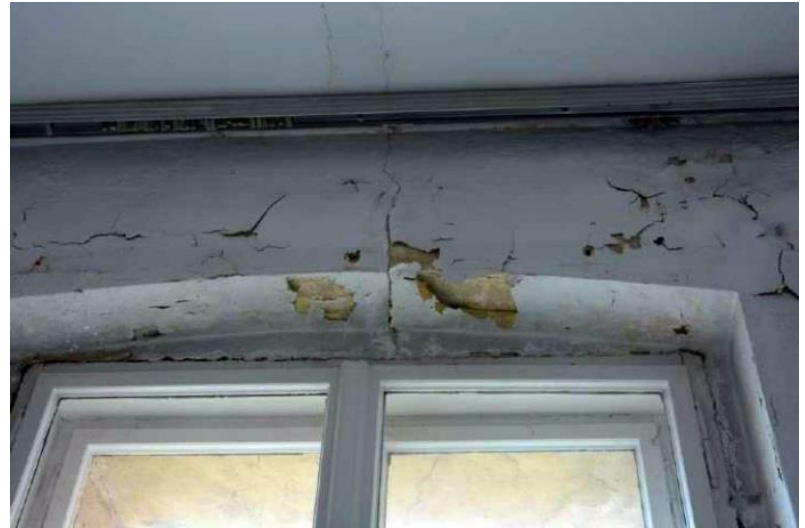

Figure 13: Exemplary cracks in lintels

In the case of the internal walls of the building, which will remain in accordance with the architectural concepts, are currently, despite damage that locally occurs in them, in a sufficient technical condition. However, the structure of most of these walls is very heterogeneous: there are numerous traces of reconstruction, holes, and masonry works. Most of the transverse walls have a large number of ventilation, exhaust and other technical ducts, which were used by the laboratories that previously existed in the building. The course of these ducts is practicality impossible todetermine. Static calculations, which were preceded by tests of masonry samples and by NDT methods, showed that the majority of the walls and
internal pillars do not have a sufficient load-beaning eapacity to transfer designed loads, and
therefore they require reinforcement with e.g. reinforced concrete sleeves. 3 CONCEPT OT TURAL PROBLEMS

Register for free at https//w.ww.scipedia.com to.download the version without the watermark the adaptation project of the historic building includes the renovation, reconstruction and change of its operation function into a public service one. The planned adaptation program for the facility also involves the use of basement floors as technical rooms. The ground floor and higher floors will be allocated for office spaces.

The design of the reconstruction of the facility for new utility purposes forces the implementation of a very wide range of demolitions (Figs 14, 15). From the existing building, only the external walls, part of the internal walls, a fragment of brick vaults above the basement in the south-east part, and a staircase located in the corner of the building will remain.

Wooden floors, Klein type slabs, ribbed Ackermann and concrete hollow brick floors are planned to be replaced with monolithic reinforced concrete floors supported on reinforced concrete ribs, as well as with a RECTOR ribbed ceiling. Because the replacement of floors and the execution of works related to the perforation of existing walls can cause secondary scratches and cracks, it is proposed to strengthen the surfaces of the walls in the FRCM (Fiber Reinforced Cementitious Matrix) system, which is based on a matrix made of mineral mortar and PBO (Polyphenylene Benzobisoxazole) fibers. 
Regarding the roof structure, it was considered to construct a reinforced concrete flat ceiling with a roof in the spatial form with a glazed aluminium structure, which would be supported on large-size reinforced concrete perimeter beams and anchored in the perimeter tie beam of the knee walls. An innovative roof construction solution also involves the use of a recessed tub for air conditioning devices in order for the roof to maintain a regular outline and for these devices to not be visible (Figs 14, 15).

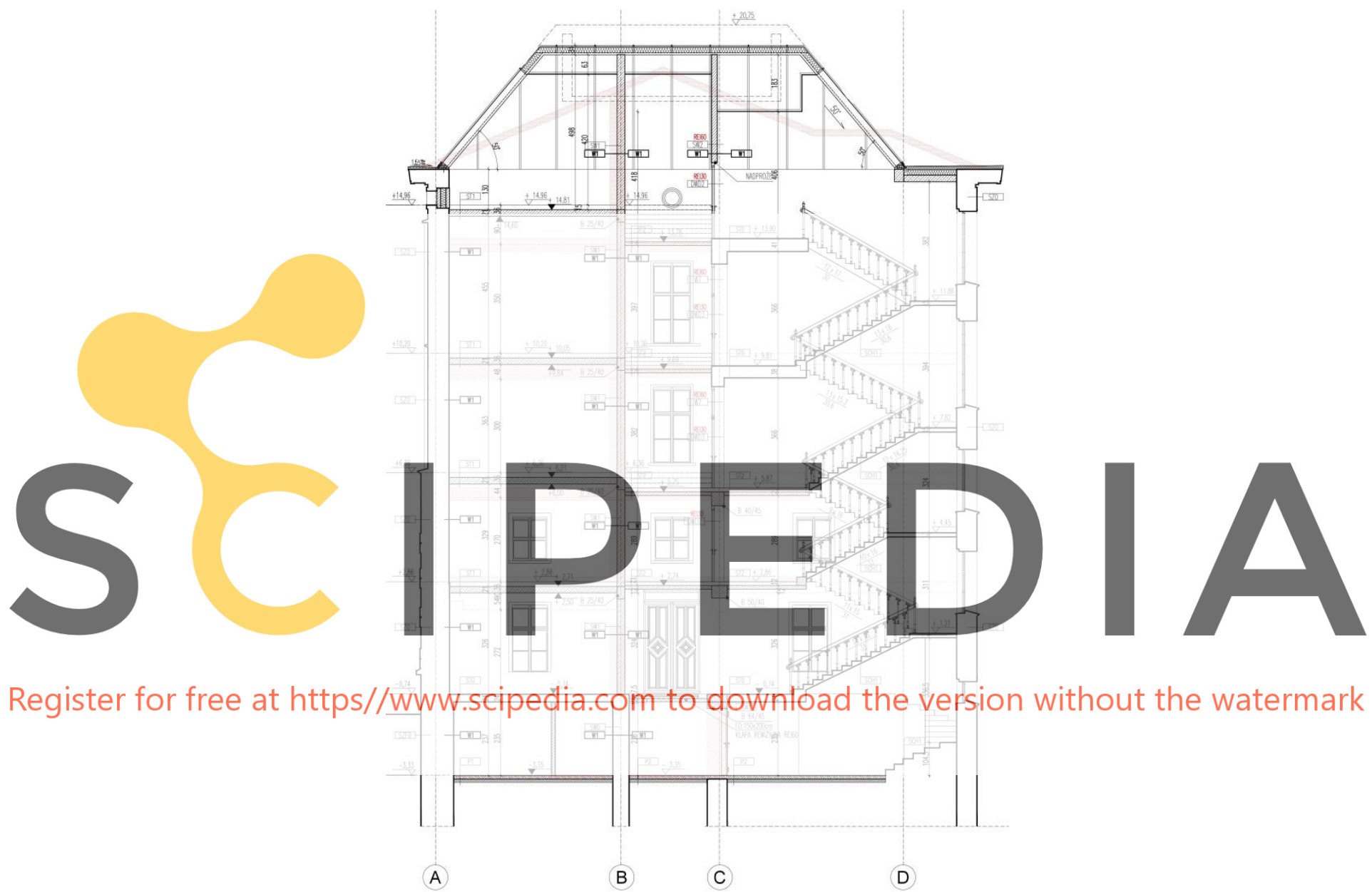

Figure 14: The cross-section (eastern wing) of the building showing the demolition plan (darkened walls) [5]

During the implementation of such a wide range of demolitions, it is very important to stage the demolition and reconstruction works. In order to adapt the building to its new form, a one-stage method of building renovation was proposed. It consists of performing demolition and reconstruction works using a combined method - partially using the "chimney" (bottomup) method, which involves demolishing the ceilings and restoring their structure from the bottom to the top, and partially using successive dismantling of the ceilings with their reconstruction being conducted from the top to the bottom of the building (Fig. 16). 


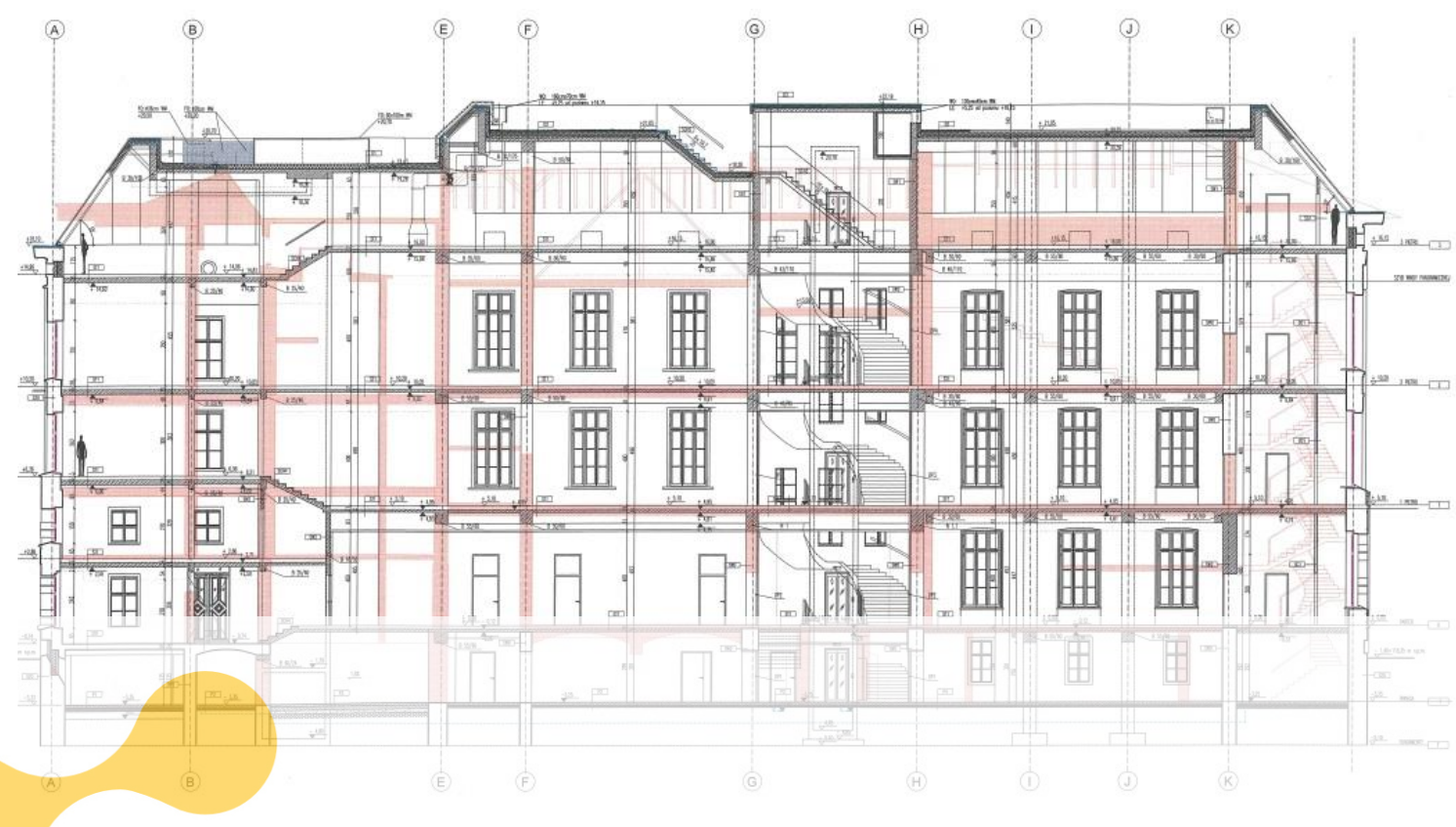

Figure 15: The cross-section (east-west direction) of the building with the demolition plan (darkened lines) [5]
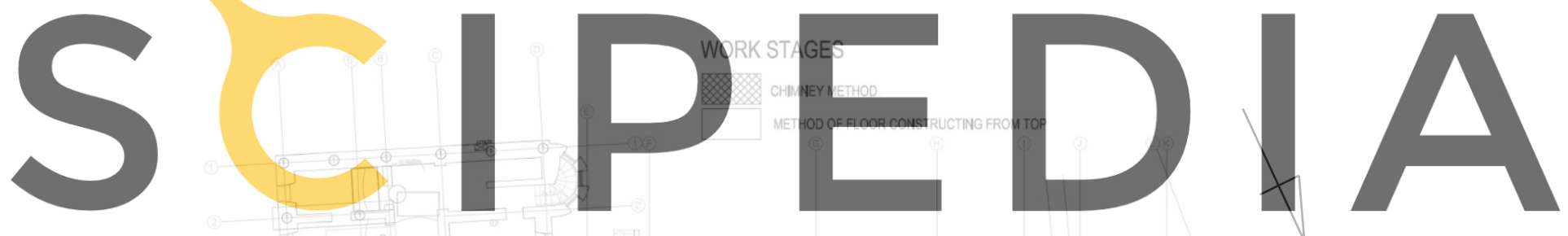

Register for free at https//www.scipedia.com to download the version without the watermark

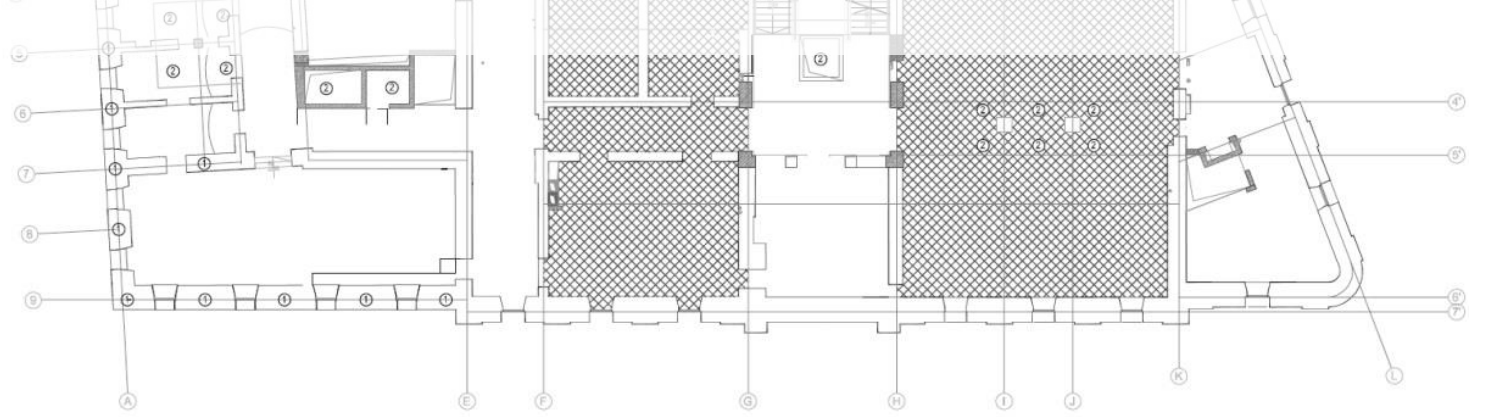

Figure 16: The plan of the combined method of renovating the building [6]

Such a solution will ensure the stability of the walls without the need to mount additional temporary steel safety elements. The proposed combined way of performing the demolition and reconstruction works will also enable the renovation time to be significantly reduced and the commissioning of the building to be faster, which will in turn translate into an economic profit of the investment and a reduction in the costs of protections. 


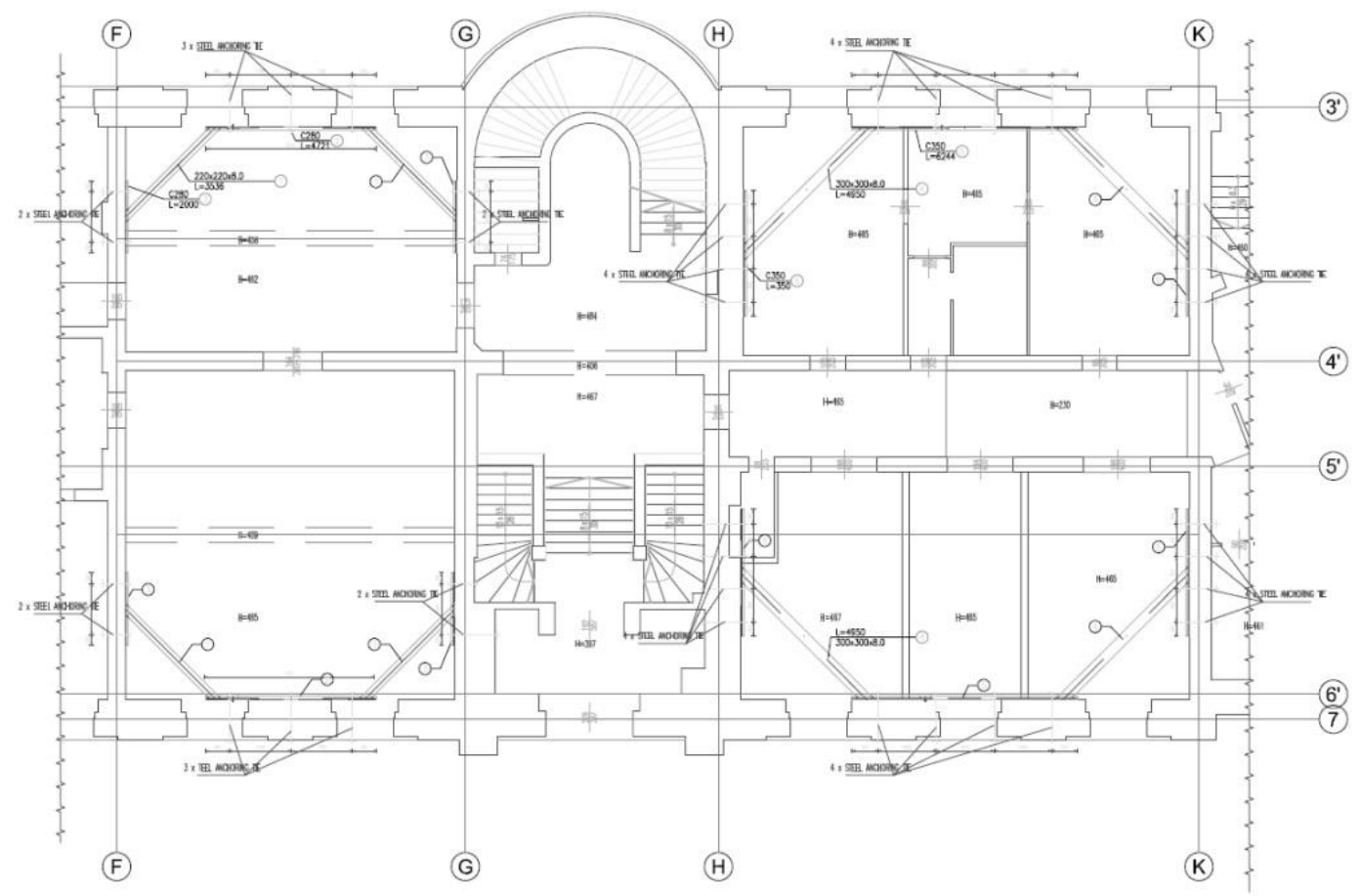

Figure 17: Scheme of wall stability protection that involves a steel structure for the "chimney" method [6]

The proposed combined building renovation technique will be carried out in one stage, and will cover a period of 1.5 years, whereas the originally planned reconstruction of individual parts was planned for 2 years and was meant to be conducted in stages.

In the part of the building where the ceilings will be demolished up to the basement ceiling, the protection of the walls' stability will involve the use of a temporary steel structure. Moreover, it is planned to reconstruct all the ceilings from the bottom to the top the hatched surface in Figure 16. Other parts of the building will be made using the method of successive demolition of ceilings and by reconstructing them from the top to the bottom of the building (Fig. 16).

The use of temporary steel protections for the walls' stability when using the "chimney" method is shown in Figure 17. The angle brace protections will be installed successively, along with the demolition of the ceilings from the top to the bottom on each floor. The angle brace protection will be installed above the demolished ceiling at a height that is equal to half of the distance between the top of the ceiling and the windowsill in the wall. Such an assembly technique will allow for a collision-free reconstruction of monolithic ceilings from the bottom to the top of the building.

\section{FINAL REMARKS}

The article presents in a general way selected aspects of the architectural and structural modernization of an old university building that was built in the first half of the 19th century. One of the requirements of the proposed adaptation was to preserve the historical context of 
the building at the same time strengthening and supplementing the value of the cultural heritage of the city of Wroclaw. All the methods of changing the building structure and adapting it to new functions were developed and applied after reaching a compromise with conservation services regarding the possibility of interference in the historical character of the building [7].

Due to the technical condition of the building, the construction design and the plan of the execution of works had to include complex works, such as:

$>$ performing jet-grouting under all the foundations of the building;

$>$ securing the stability of the building's walls along their entire height due to the very wide range of necessary demolitions;

use of modern floors;

$>$ preserving the form and shape of the roof, which was designed to contain all the technical equipment (incl. HVAC and fire protection systems).

The most challenging works connected to the building refurbishment are demolitions of some of its structural elements (walls and floors) with parallel construction of the necessary temporal stability structural strengthening. These works are planned to be performed at the same time in two ways, depending on the range of demolition: bottom-up method in which demolishing of the ceilings and restoring their structure is done from the bottom to the top, and up-down method in which dismantling of the ceilings with their reconstruction are to be conducted from the top to the bottom of the building. The proposed combined building renovation technique will cover a period of 1.5 years, whereas the originally planned reconstruction of individual parts was planned for 2 years.

\section{REFERENCES}

[1] Kodzis, E. Wroctawskie Kamienice. Grodzka 9. Available online: http://wroclawskiekamienice.blogspot.com/2015/09/ul-grodzka-9.html, Accessed: 9 January 2020 (in Polish).

[2] https://fotopolska.eu/Wroclaw/b9533,Grodzka_9_-_Szewska_38-39.html?f=105513-foto.

[3] Building Archive of City of Wroclaw.

[4] https://fotopolska.eu/Wroclaw/b9533,Grodzka_9___Szewska_38-39.html?f=704451-foto.

[5] Architectural design of reconstruction, renovation and change of use of a public building at ul. Grodzka 9 in Wroclaw, Maćków Design Office, (2016).

[6] Technical expertise of a public building at ul. Grodzka 9 in Wroclaw, VEGACAD Design and Implementation Office, (2019).

[7] Roca, P., Lourenco, P.B. and Gaetani, A. Historic Construction and Conservation. Materials, Systems and Damage. Routledge, (2019). 